\title{
Monsteroideae (Araceae) no estado do Paraná, Brasil
}

\author{
Monsteroideae (Araceae) from Paraná, Brazil
}

\author{
Stephanie de Fatima Pereira ${ }^{1,3} \&_{\text {Livia Godinho Temponi }}^{2}$
}

\begin{abstract}
Resumo
O trabalho apresenta o tratamento taxonômico das Monsteroideae (Araceae) nativas do Brasil encontradas no estado do Paraná, com uma chave de identificação, descrições e ilustrações das espécies. As coletas foram realizadas de julho de 2013 a setembro de 2014 e os espécimes coletados foram identificados e depositados no UPCB e UNOP. Também foram analisados 61 exsicatas que se encontram distribuídas nos herbários do estado. Foram encontradas quatro espécies nativas do Brasil: Heteropsis rigidifolia, H. salicifolia, Monstera adansonii e M. praetermissa. Além dessas, foram encontradas em áreas antropizadas de Unidades de Conservação as espécies exóticas do Brasil: E. pinnatum e M. deliciosa, para as quais são apresentadas fotos ilustrativas para seu reconhecimento em campo. Com relação às espécies nativas do Brasil, $M$. adansonii é neotropical com distribuição em vários estados do país, enquanto Heteropsis rigidifolia, H. salicifolia e M. praetermissa são endêmicas do Brasil e apresentam distribuição restrita à Mata Atlântica. Para as duas últimas o estado do Paraná é o limite sul de distribuição geográfica. No Paraná todas as espécies nativas de Monsteroideae ocorrem exclusivamente em áreas de Floresta Ombrófila Densa.

Palavras-chave: Epipremnum, flora do Paraná, Heteropsis, Monstera, taxonomia.

Abstract

The study presented in this paper is a taxonomic treatment with an identification key, descriptions and illustrations of Monsteroideae (Araceae) species, located in the Paraná state (Brazil). The specimens were collected from July 2013 to September 2014, identified and deposited at UPCB and UNOP. Sixty-One exsiccates distributed in the herbaria of the Paraná were analyzed, the study revealed that the species: $H$. rigidifolia, H. salicifolia, M. adansonii and M. praetermissa are native to Brazil, and the exotic E. pinnatum and $M$. delicious were found in disturbed areas of conservation units. They are represented in this study by illustrative photos for their recognition in the field. Furthermore, the native species M. adansonii is neotropical and distributed in several states of Brazil, while H. rigidifolia, H. salicifolia and M. praetermissa are endemic to Brazil and more restricted to the Atlantic Forest. The Paraná state is the southern limit of geographical distribution for $H$. salicifolia and M. praetermissa. In Paraná, all native species Monsteroideae are found exclusively in areas of Ombrophylous Dense Forest.
\end{abstract}

Key words: Epipremnum, flora of Paraná, Heteropsis, Monstera, taxonomy.

\section{Introdução}

As Araceae Juss. são reconhecidas pela inflorescência em espádice acompanhada por uma bráctea, a espata (Grayum 1990; Mayo et al. 1997). São representadas por aproximadamente 120 gêneros e 3020 espécies (Boyce \& Croat
2013). Encontram-se distribuídas em todo território brasileiro (BFG 2015), ocorrendo em diversas formações vegetacionais, como florestas, restingas, campos e afloramentos rochosos (Coelho et al. 2009). Possuem diferentes formas de vida, mas $70 \%$ delas são epífitas ou hemiepífitas (Grayum 1990).

\footnotetext{
'Universidade Federal do Paraná, Centro Politécnico, Depto. Botânica, Av. Coronel Francisco Herácito dos Santos 100, Jardim das Américas, 80060-240, Curitiba, PR, Brasil.

${ }^{2}$ Universidade Estadual do Oeste do Paraná, CCBS, R. Universitária 2069, 85819-110, Cascavel, PR, Brasil.

${ }^{3}$ Autor para correspondência: stephaniefpereira133@gmail.com
} 
As Araceae são pertencentes ao clado das Alismatales (APG IV 2016), distribuídas em oito subfamílias (Cabrera et al. 2008; Henriquez et al. 2014), sendo Monsteroideae Engl., uma das subfamílias mais basais (Mayo et al. 1997).

Muitas espécies de Monsteroideae são utilizadas na ornamentação, como o lírio-da-paz (Spathiphyllum spp.), costela-de-adão (Monstera deliciosa Liebm.), jiboia [Epipremnum pinnatum (L.) Engl.] (Souza \& Lorenzi 2012). Os cipóstitica (Heteropsis spp.), fazem parte da economia extrativista da Amazônia, são considerados fontes de fibras resistentes, e suas raízes também são utilizadas para produção de artesanatos em geral (Soares Morais 2008).

Para Keating (2004), este grupo era considerado uma tribo, pertencendo a subfamília Pothoideae Engl. Após estudos recentes de Cabrera et al. (2008) e Henriquez et al. (2014) nos quais o grupo emerge como monofiléticos vem sendo tratado novamente como uma das oito subfamílias de Araceae.

Monsteroideae possui como características: pecíolo geniculado apicalmente, bainha geralmente longa, quase igualando ao pecíolo (exceto em Alloschemone Schott e Amydrium Schott), espata indiferenciada em tubo e lâmina, decídua e perigônio presente ou ausente (Mayo et al. 1997).

A subfamília ocorre na América do Sul, África, sudeste da Ásia até o Pacífico e é subdividida em quatro tribos: Spathiphylleae Engl., Anadendreae Bogner \& French, Heteropsideae Engl., e Monstereae Engl., sendo as três últimas monofiléticas (Tam 2004). Tam (2004), aponta a necessidade de mais estudos com o intuito de esclarecer melhor a relação parafilética e complexa entre os gêneros de Monsteroideae.

Em termos revisionais Monsteroideae é ainda um grupo pouco estudado. Engler \& Krause (1908) fizeram uma revisão para o gênero Heteropsis Kunth, e após este estudo apenas recentemente foi publicada uma nova revisão para o gênero por Soares et al. (2013). Para Monstera Adans, apesar das revisões de Engler \& Krause (1908) e Madson (1977), ampliação na área de ocorrência de algumas espécies do grupo, assim como espécies novas continuam sendo publicadas (Gonçalves \& Temponi 2004; Karney \& Grayum 2012), evidenciando a necessidade de estudos no grupo.

O presente estudo objetiva realizar o tratamento taxonômico de Monsteroideae no estado do Paraná, com descrições, chave de identificação, ilustrações, mapa de distribuição e comentários taxonômicos.

\section{Material e Métodos}

No estado do Paraná ocorre um predomínio do bioma Mata Atlântica (IBGE 2010; Maack 1981), mas podem ser encontradas cinco grandes formações fitogeográficas: Floresta Ombrófila Densa, Floresta Ombrófila Mista, Floresta Estacional Semidecidual, Estepe (campos) e Savana (cerrado) (Roderjan et al. 2002).

O levantamento das Monsteroideae baseouse em análise de 61 exsicatas depositadas nos principais herbários do estado: HCF, FUEL, HUEM, HUPG, MBM, UNOP, UPCB; e herbários de grande importância para a família, como RB e HBR (siglas de acordo com Thiers, continuamente atualizado) e de amostras coletadas em diferentes parques nacionais e estaduais do Paraná.

As coletas foram realizadas de julho de 2013 a setembro de 2014 e as amostras herborizadas segundo técnicas descritas por Bridson \& Forman (2004). Os nomes dos autores foram abreviados de acordo com Brummit \& Powell (1992), e a terminologia utilizada nas descrições dos táxons foi baseada em Radford et al. (1974) e Stearn (2004).

Para descrição das lâminas foliares foram analisadas amostras adultas. As informações sobre fenologia e distribuição geográfica foram obtidas a partir das etiquetas de exsicatas examinadas, expedições a campo e bibliografia. Os materiais encontram-se incorporados no herbário UNOP e suas duplicatas enviadas aos herbários UPCB e MBM.

\section{Resultados e Discussão}

Foram registradas quatro espécies nativas do Brasil para o estado do Paraná, distribuídas nos gêneros Heteropsis Kunth. e Monstera Adans.

O gênero Heteropsis é exclusivo da América Tropical (Mayo et al. 1997). No Brasil, o maior número de espécies ocorre na Amazônia, com exceção de quatro espécies que são encontradas na Mata Atlântica, Heteropsis flexuosa (Kunth) G.S.Bunting, Heteropsis oblongifolia Kunth, Heteropsis rigidifolia Engl e $H$. salicifolia Kunth (Soares et al. 2013), sendo as duas últimas encontradas no Paraná. O estado do Paraná é considerado o limite sul de distribuição para $H$. salicifolia (BFG 2015).

O gênero Monstera também é exclusivo da América Tropical (Mayo et al. 1997). No Brasil ocorrem nove espécies, a maioria na região Amazônica (BFG 2015). Para o Paraná foram 
registradas duas espécies nativas do Brasil: Monstera adansonii Schott e M. praetermissa E.G.Gonç. \& Temponi. A primeira espécie é neotropical, amplamente distribuída em vários estados brasileiros (BFG 2015). Já M. praetermissa ocorre nos estados Bahia, Ceará, Pernambuco, Goiás, Espírito Santo, Minas Gerais, Rio de Janeiro, São Paulo, Paraná e Santa Catarina (BFG 2015).

\section{Chave de identificação das espécies de Monteroideae nativas do Brasil encontradas no Paraná}

1. Pecíolo até $1 \mathrm{~cm}$ de compr., lâmina foliar nunca fenestrada

2. Lâmina foliar com ápice agudo e base obtusa, nervura coletora distante até $1,3 \mathrm{~mm}$ da margem. 1. Heteropsis rigidifolia

2'. Lâmina foliar com ápice longo cuspidado e base cuneada, nervura coletora distante mais de 1,3 mm da margem. 2. Heteropsis salicifolia

1'. Pecíolo mais que $6 \mathrm{~cm}$ de compr., lâmina foliar geralmente fenestrada

3. Bainha persistente, genículo $2-3 \mathrm{~cm}$, lâmina foliar geralmente fenestrada, fenestras nunca atingindo a margem, espata 11-22 cm, creme a amarelado, flores basais estéreis, infrutescência creme a esverdeada. 3. Monstera adansonii

3'. Bainha decídua, genículo 0,7-1.9 cm, lâmina foliar sempre fenestrada, fenestras próximas a atingindo a margem, espata 3-5 cm, amarelo alaranjado, flores funcionais em toda o espádice, infrutescência alaranjada... 4. Monstera praetermissa

Tratamento taxonômico 1. Heteropsis rigidifolia Engl., Das Pflanzenreich. IV.23B (21): 51. 1905.

Figs. 1h,i; 2a

Hemiepífita. Caule 0,2 cm diâm., entrenós $1,5-7,5 \mathrm{~cm}$ compr; profilo não visto. Bainha peciolar não vista; pecíolo $0,2-0,8 \mathrm{~cm}$ compr., castanho; genículo $0,3 \mathrm{~cm}$ compr. Lâmina foliar elíptica, 7-21,5 × 2-6 cm, fenestras ausentes, ápice agudo, base obtusa, verde amarronzada, levemente discolor, coriácea, máculas ausentes. Nervura coletora distante $0,1-1,3 \mathrm{~mm}$ da margem. Inflorescência 1 por axila foliar, pedúnculo castanho, $0,2-1 \mathrm{~cm}$, ereto; espata largamente oval, 1,8-3,5 × $1 \mathrm{~cm}$, alva; espádice homogêneo, cilíndrico a oval cilíndrico, 1,8-2,5 × 0,6-1,2 $\mathrm{cm}$ creme; estípite $0,2 \mathrm{~cm}$. Flores bissexuais aclamídeas, 4 estames, livres, anteras rimosas, gineceu prismático $0,3 \times 0,4 \mathrm{~cm}$, ovário creme, 2 lóculos incompletos, placentação basal a subbasal, região estilar densa, mais larga que o ovário, estigma elipsóide. Espádice em frutificação 3-7,5 $\times 1,4-3 \mathrm{~cm}$, pedúnculo ereto. Bagas verdes a alaranjadas, $0,3-0,8 \times 0,4-0,5 \mathrm{~cm}$.

A espécie pode ser reconhecida por sua lâmina foliar coriácea e rígida, com nervura coletora até 1,3 $\mathrm{mm}$ da margem, bagas verde a alaranjadas. Pode ser confundida com $H$. salicifolia, que tem o ápice da lâmina foliar longo cuspidado, a lâmina coriácea a cartácea, com nervura coletora maior que 1,3 mm da margem. Encontrada em flores entre os meses de setembro a dezembro e em frutos em janeiro.
É endêmica do Brasil, encontrada na Mata Atlântica, Nordeste (BA), Sudeste (ES, MG, RJ, SP) e Sul (PR, RS) (Soares et al. 2013) no interior de matas secundárias ou bordas de mata como hemiepífitas (Soares et al. 2013). No Paraná foi encontrada em seis localidades de Floresta Ombrófila Densa (Fig. 3).

Material examinado: Antonina, Estrada Cacatu-Serra Negra, 19.I.1966, fr., G. Hatschbach 13555 (MBM); Reserva Natural do Rio Cachoeira, 9.XII.2010, L.G. Temponi et al. 922 (UNOP). Guaraqueçaba, Rio Bananal, 8.XII.1970, fl., G. Hatschbach 25763 (MBM). Guaratuba, Serra do Mar, resgate da flora linha de transmissão elétrica Curitiba a Joiville, 7.IX.2013, fl., M.E. Engels 1526 (MBM). Morretes, 24.I.1969, fr., G. Hatschbach 20901 (MBM); Pedra Branca de Araraquara, 5.XI.1961, fl., G. Hatschbach 8696 (MBM, UPCB e HBR). Paranaguá, Ilha do Mel, Morro Bento Alves, 13.XI.1999, fl., C. Kozera, et al. 1320 (MBM e UPCB); Morro do Caiobá, 30.X.1959, fl., G. Hatschbach 6414 (MBM, UPCB, PKDC); Hotel Mata Atlântica, 27.XI. 2012. fl. F. Rocha et al. 88 (UNOP, UPCB).

2. Heteropsis salicifolia Kunth, Enum. P1. 3: 60 (1841). Figs. $1 \mathrm{j}, \mathrm{k} ; 2 \mathrm{~b}$

Hemiepífita. Caule $0,2 \mathrm{~cm}$ de diâm., entrenós $0,8-3,5 \mathrm{~cm}$ compr.; profilo não visto. Bainha peciolar adnata ao entrenó; pecíolo $0,2-0,7 \mathrm{~cm}$ compr.; genículo $0,3 \mathrm{~cm}$. Lâmina foliar elíptica a oval elíptica, 6-18 × 2,5-4,5 cm, fenestras ausente, ápice longo cuspidado, cúspide $0,5-4 \mathrm{~cm}$ compr., base cuneada, verde, concolor, cartácea, 


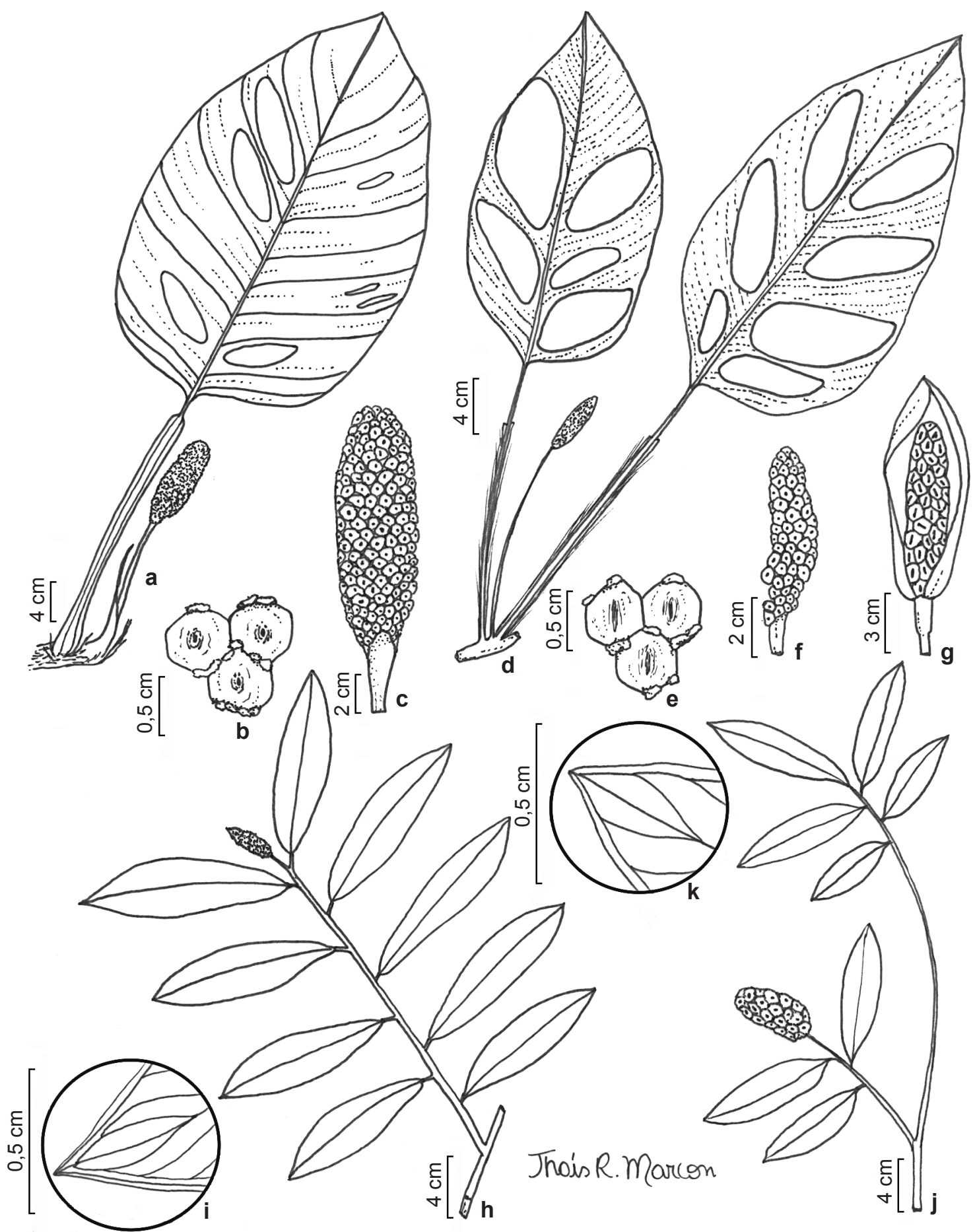

Figura 1 - a-c. Monstera adansonii - a. hábito, fenestras nunca atingindo a margem; b. detalhe das flores bissexuais; c. inflorescência. d-g. Monstera praetermissa-d. hábito, fenestras próximas a atingindo a margem; e. detalhe das flores bissexuais; f. inflorescência; g. detalhe da infrutescência .h-i. Heteropsis rigidifolia - h. hábito; i. detalhe da nervura coletora menor que $1,3 \mathrm{~cm}$. j-k. Heteropsis salicifolia - j. hábito; k. detalhe da nervura coletora maior que 1,3cm.

Figure 1 - a-c. Monstera adansonii - a. habit, perforated never reaching the margin; b. detail of bisexual flowers; c. inflorescence. d-g. Monstera praetermissa - d. habit, perforated near reaching the margin; e. detail of bisexual flowers; f. inflorescence; g. detail of inflorescence. h-i. Heteropsis rigidifolia - h. habit; i. detail of collective vein less than $1.3 \mathrm{~cm}$. j-k. Heteropsis salicifolia - j. habit; $\mathrm{k}$. detail of collective vein bigger than $1.3 \mathrm{~cm}$. 

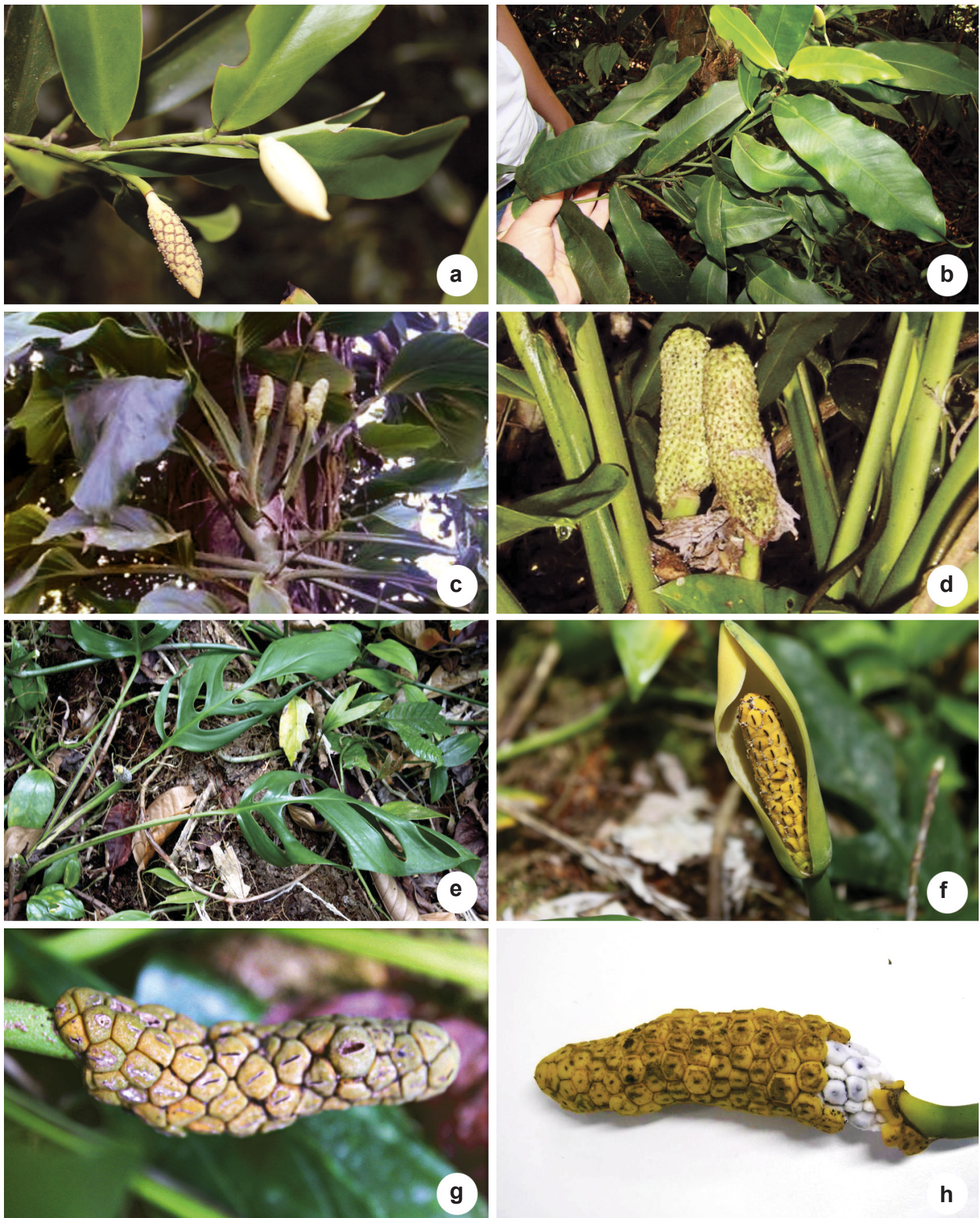

Figura 2 - a. Heteropsis rigidifolia - lâmina foliar com inflorescência. b. Heteropsis salicifolia - lâmina foliar. c,d. Monstera adansonii - c. hábito; d. infrutescência. e-h. Monstera praetermissa - e. lâmina foliar; f. inflorescência; g. fruto imaturo; h. fruto maduro. Fotos: a,b. L.G. Temponi; c,d. L.C. Ferneda Rocha; e-h. L.S.B. Calazans; b. M.E. Engels. Figure 2 - a. Heteropsis rigidifolia - leaf blade with inflorescence. b. Heteropsis salicifolia - leaf blad. c,d. Monstera adansonii - c. habit; d. spadix fruiting. e-h. Monstera praetermissa - e. leaf blade; f. inflorescence; g. i mmature fruit; h. mature fruit. Photos: a,b. L.G. Temponi; c,d. L.C. Ferneda Rocha; e-h. L.S.B. Calazans; b. M.E. Engels. 
máculas ausente. Nervura coletora distante mais de 1,3 $\mathrm{mm}$ da margem. Inflorescência 1 por axila foliar, pedúnculo, castanho esverdeado 3-5 $\mathrm{mm}$, ereto; espata oval, 1,3-2 × 0,7 cm, decídua após antese, amarelo esverdeada; espádice homogênea, cilíndrico, 1-5 × 0,6 cm compr., creme; estípite $1 \mathrm{~mm}$. Flores bissexuais aclamídeas, 4 estames, livres, anteras rimosas, gineceu prismático 0,2 $\times 0,3 \mathrm{~cm}$, ovário creme, 2 lóculos incompletos, placentação basal a sub-basal, região estilar densa, mais larga que o ovário, estigma oblongo. Espádice em frutificação 2-3,5 × 0,6 cm, pedúnculo ereto. Bagas amarelas a vermelhas, 0,7-1,2 ×0,5-0,8 cm.

É uma espécie muito ramificada, ocorrendo abaixo de $10 \mathrm{~m}$ de altura em mata sombreada (Soares 2008). Pode ser confundida com $H$. rigidifolia que se diferencia por possuir ápice da lâmina foliar agudo, com nervura coletora até $1,3 \mathrm{~mm}$ da margem. Encontrada com flores entre dezembro e janeiro e com frutos em fevereiro.

Endêmica do Brasil e da Mata Atlântica e ocorre no Nordeste (BA), Sudeste (ES, MG, RJ, SP) e Sul (PR) (BFG 2015). No Paraná foi encontrada em três regiões de Floresta Ombrófila Densa (Fig. 3), sendo uma espécie pouco amostrada no estado. Material examinado: Antonina, Rio Pequeno, 10.I.1974, fl., G. Hatschbach 33642 (MBM). Guaratuba, 10.XII.1971, fl., Pe. L. Krierger 11094 (RB). Paranaguá, Parque Estadual Floresta do Palmito I.II.2014, fr., M. E. Engels et al. 2367 (MBM).

3. Monstera adansonii Schott, Wien Z. Kunst. 4: 1028. 1830 .

Figs. 1a-c; 2c,d

Hemiepífita. Caule 1,5-2,2 cm diâm., entrenó 3-6 cm compr.; profilo 9,5-28 cm, verde passando a pardo quando seco. Bainha peciolar permanente, longa atingindo o genículo, mesmo comprimento do pecíolo; pecíolo 13-59 cm compr., canaliculado; genículo 2-3 cm. Lâmina foliar elíptico-ovada 14,2-66,5 × 9,5-46 cm, geralmente fenestrada, fenestras atingindo nunca atingindo a margem, ápice agudo, base cuneada a arredondada, verde nítido na face adaxial, amarelada na abaxial, levemente discolor, cartácea, máculas ausente, margem inteira. Nervuras laterais primárias 8-21 pares, nervura coletora ausente. Inflorescência 1 por axila foliar, pedúnculo castanho esverdeado, 4,8-25 cm, ereto; espata ovada $11-22 \times 2-18 \mathrm{~cm}$, decídua após antese, creme a amarelo pálida com margem esverdeada; espádice homogêneo, não adnato a espata, 6,4-17× 1-3 cm, creme; estípite não visto. Flores bissexuais aclamídeas, 4 estames, livres, antera rimosa, gineceu prismático $0,8-1,2 \times 0,3-0,4 \mathrm{~cm}$, ovário creme, 2 lóculos completos, placentação axial-basal, região estilar mais larga que o ovário, alva, 2, estigma alongado, fendido no centro, levemente alaranjado na antese. Espádice em frutificação 15-20,5 × 2-2,9 $\mathrm{cm}$, pedúnculo ereto. Bagas creme a esverdeadas, $1-1,2 \times 0,4-0,6 \mathrm{~mm}$.

A espécie é semelhante à $M$. deliciosa, da qual se diferencia por esta apresentar lâmina foliar fenestrada e recortada, com base cordada, enquanto M. adansonii apresenta lâmina foliar apenas fenestradas, com base cuneada a arredondada. Encontrada com flores entre outubro e fevereiro e com frutos entre março e julho.

É amplamente distribuída no Brasil, encontrada na Amazônia, Mata Atlântica, Caatinga e Cerrado, encontrada em borda e interior da mata (BFG 2015). No Paraná foi encontrada em seis localidades da Floresta Ombrófila Densa (Fig. 3). Material examinado: Antonina, Areia Branca, 7.III.1974, fr., G. Hatschbach 34290 (MBM); Bairro Alto 5.II.1983, fl., G. Hatschbach 46084 (MBM). Guaraqueçaba, Reserva Natural de Salto Morato, 18.IV.1999, fl., A.L.S. Gatti \& G. Gatti 261 (UPCB, UEM); 16.VIII.1998, fl., G. Gatti \& A.L.S. Gatti 468 (UPCB, UEM); 15.VIII.1998, fl., A.L.S. Gatti \& G. Gatti 260 (UPCB); 26.II.1969, fl., G. Hatschbach \& G.M. Barroso 960 (MBM); Km 5-10 da rod. para Antonina 23.VII.1992, fl., G. Hatschbach \& O.S. Ribas 57133 (MBM). Guaratuba, 26.VII.1974, fl., Pe. L. Krierger 13344 (RB); 9.V.1996, fr., C.V. Roderjan \& G. Tiepolo 1281 (MBM); 19.VII.1959, fl., G. Hatcschbach \& G.M. Barroso 960 (MBM, RB, PKDC); Parque Nacional Saint Hilaire \& Lange, Salto Parati, 20.X.2013, fr. A.P. Cardozo et al. 92 (MBM, UNOP e UPCB); Rio Tupitinga 29.IV.1972, fr., G. Hatschbach 29630 (MBM). Matinhos, Estrada Alexandra-Matinhos 29.IV.1999, fr., C. Kozera et al. 1070 (MBM e UPCB); 29.IV.1999, fr., C. Kozera et al. 1069 (UEM). Morretes, 8.X.2005, fl., M.G. Caxambu 875 (MBM e UNOP); 18.VII.1995, fl., S.R. Ziller \& W. Maschio 849 (MBM); Rio Mãe Catira 14.IV.1957, fl., L.B. Smith \& G. Hatschbach 3931 (MBM e HBR); Rio Marumbi 10.III.1983, fr., G. Hatschbach 46251 (MBM). Paranaguá, X.1999, fl., R. Kersten 2001 (UPCB); 30.V.1999, fr., C. Koreza 1107 (UPCB); BR-407 - próximo a Floresta Estadual do Palmito, 5.VII.2013, fr., S.F. Pereira et al. 260 (UNOP e UPCB); Hotel Mata Atlântica, Trilha Figueira-Cahoeira, 27.XI.2012, fr., L.C. Ferneda Rocha et al. 87 (UNOP e UPCB); Ilha do Mel, Morro de Bento Alves, 30.V.1999, fl., C. Kozera et al. 1107 (MBM, UEM); Morro do meio, 11.III.1988, fl., R.M. Britez 1830 (PKDC); 20.III.1987, fl., W.S. Souza 688 (UPCB); 13.II.1987, fl., W.S. Souza 561 (MBM, UEL, UPCB, PKDC); 12.VII.1986, fr., R.M. Britez \& W.S. Souza 779 (MBM e PKDC); Morro do Tabaquara 22.IV.1967, fl., G. Hatschbach 16374 (MBM); Rio Cambará 29.V.1968, fr., G. Hatschbach 19242 (MBM); Rio São João 15.IX.1953, fl., P.R. Reitz 5737 (HBR). 

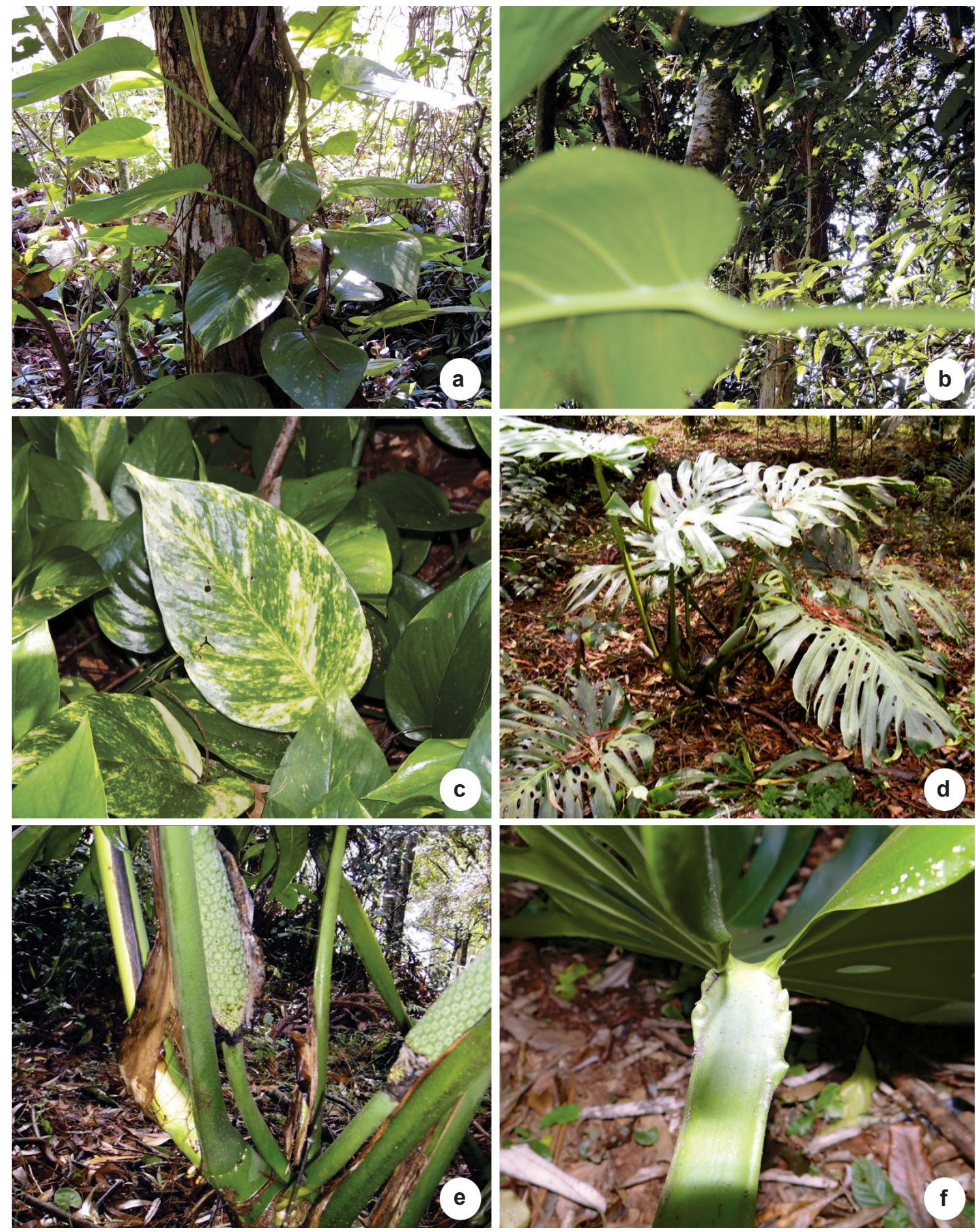

Figura 3 - a-c. Epipremnum pinnatum - a. hábito; b. geniculado apicalmente; c. lâmina foliar variegada. d-f. Monstera deliciosa - d. hábito; e. infrutescência; f. genículo. Fotos: a-f. C.V. Buturi.

Figure 3 - a-c. Epipremnum pinnatum - a. habit; b. geniculate apically; c. variegated leaf. d-f. Monstera deliciosa - d. habit; e. infruteescense; f. geniculate apically. Photos: a-f. C.V. Buturi. 
4. Monstera praetermissa E.G.Gonç. \& Temponi, Brittonia 56(1): 72-74. 2004. Figs. 1d-g; 2e-h Hemiepífita. Caule 0,7-1 cm diâm., entrenó $2,5-9 \mathrm{~cm}$, profilo não visto. Bainha peciolar longa decídua até o genículo, $15,5 \mathrm{~cm}$ compr.; pecíolo 6,2-24 cm compr., sulcado na face adaxial, apicalmente geniculado; genículo 0,7-1.9 $\mathrm{cm}$. Lâmina foliar ovado-elíptica, levemente assimétrica, $18,5-32 \times 5-13,4 \mathrm{~cm}$, sempre fenestrada, fenestras atingindo a margem, ápice agudo-acuminado, base cuneado-obtusa, verde escuro, concolor, cartácea, máculas ausente, margem inteira. Nervuras laterais primárias 12 pares, formando uma nervura coletora marginal irregular. Inflorescência 1 por axila foliar, pedúnculo verde, 6,9-14,5 cm, ereto; espata oblonga 3-5 × 1,8-3 cm, decídua após antese, amarelo-alaranjada externa e internamente; espádice homogêneo, $3,5-7,5 \times 1-1,4 \mathrm{~cm}$, amarelo-alaranjado, estípite não visto. Flores bissexuais aclamídeas, 4 estames, livres, anteras rimosas, gineceu prismático, $3-5 \times 3,5-5,5 \mathrm{~mm}$, ovário creme, 2 lóculos incompletos, região estilar mais larga que o ovário, alaranjada, placentação axial-basal, estigma alongado, fendido no centro, marrom. Espádice em frutificação, 3,7-7,2 $\times$ $1,1-4,5 \mathrm{~cm}$, pedúnculo curvado no ápice. Bagas alaranjadas, $0,7-0,95 \times 0,65-0,85 \mathrm{~cm}$.

Monstera praetermissa é facilmente reconhecida por ter bainha decídua, a lâmina foliar mesmo jovem já fenestrada, com estas atingindo a margem. A espata é amarelo alaranjado, com flores funcionais em todo o espádice. Foi encontrada com flores em julho e com frutos em janeiro.

Foi encontrada em alguns herbários registrada como Monstera obliqua Miq., porém esta é uma identificação errônea. Monstera obliqua se diferencia de $M$. praetermissa principalmente por apresentar de 1 a 4 inflorescências por simpódio floral, enquanto M. praetermissa tem apenas uma inflorescência por simpódio floral e também por não ocorrer no leste do Brasil, sendo exclusivo da região Amazônica (Gonçalves \& Temponi 2004).

Endêmica do Brasil é encontrada principalmente na Mata Atlântica e ocorre no Nordeste (BA, CE, PB), no Centro-Oeste (GO), no Sudeste (ES, MG, RJ e SP) e Sul (PR) (BFG 2015). No Paraná foi encontrada em três localidades de Floresta Ombrófila Densa (Fig. 3). Material examinado: Cerro Azul, 8.VII.1966, fl., J.C. Lindeman \& J.H. de Haas 2125 (RB e HBR).
Guaraqueçaba, Reserva Natural Salto Morato, 23.I.1999, fr., G. Gatti \& A.L.S. Gatti 318 (UPCB, UEM). Guaratuba, Parque Nacional Saint-Hilaire \& Lange, 20.X.2013, fr., L.C. Ferneda Rocha et al. 284 (UNOP); 20.X.2013, fr. A.P. Cardozo et al. 91 (MBM, UNOP e UPCB)

Além das quatro espécies nativas do Brasil, foram encontradas em áreas antropizadas de Unidades de Conservação as espécies exóticas do Brasil: E. pinnatum (L.) Engl e M. deliciosa. Epipremnum pinnatum é popularmente conhecida como jiboia, originária das Ilhas Salomão (Lorenzi \& Souza 1995) e pode ser reconhecida pelas folhas variegadas de amarelo ou branco (Fig. 3a-c). Monstera deliciosa Lieebm. é popularmente conhecida como costela-deadão, originária do México (Lorenzi \& Souza 1995) e pode ser reconhecida por ser uma erva rizomatosa robusta com folhas além de fenestrada e recortadas (Fig. 3d-f).

A Mata Atlântica é considerada uma das áreas de maiores concentrações de espécies endêmicas e maiores pressões em perdas de habitat (Myers et al. 2000), o que se confirma também com este estudo, pois $75 \%$ das espécies nativas de Monsteroideae no Paraná ( $H$. rigidifolia, $H$. salicifolia e $M$. praetermissa) são restritas a Mata Atlântica. Todas estas espécies foram exclusivas da Floresta Ombrófila Densa, que ocorre na porção leste do estado, uma região com temperaturas elevadas e altos índices de precipitação (Maack 1981; Roderjan et al. 2002), favorecendo a ocorrência de epífitas e hemiepífitas.

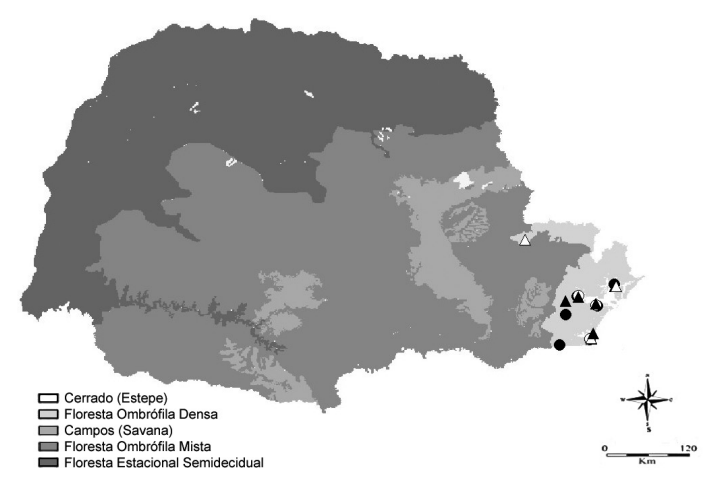

Figura 4 - Distribuição geográfica no estado do Paraná - Heteropsis rigidifolia $(\bullet) ;$ H. salicifolia $(0)$; Monstera adansonii ( $\mathbf{\Delta}) ;$ M. praetermissa $(\Delta)$.

Figure 4 - Geographic distribuition in the state of Paraná Heteropsis rigidifolia $(\bullet)$; H. salicifolia $(0)$; Monstera adansonii $(\mathbf{\Delta})$; M. praetermissa $(\Delta)$. 


\section{Agradecimentos}

À CAPES, a bolsa de Mestrado concedida à primeira autora; à Fundação Araucária (chamada pública 21/2012), a bolsa de produtividade concedida à segunda autora. Aos revisores e editores de área que contribuíram com este manuscrito. Aos colegas de Mestrado no auxílio em campo.

\section{Referências}

APG IV - The Angiosperm Phylogeny Group (2016) An update of the Angiosperm Phylogeny Group classification for the orders and families of flowering plants. Botanical Journal of the Linnean Society 181:1-20.

BFG - The Brazil Flora Group (2015) Growing knowledge: an overview of seed plant diversity in Brazil. Rodriguésia 66: 1085-1113.

Boyce PC \& Croat TB (2013) The überlist of Araceae, totals for published and estimated number of species in Aroid genera. Disponível em $<$ http:// www.aroid.org/genera/130307uberlist.pdf $>$. Acesso em 9 junho 2014.

Bridson D \& Forman L (2004) The herbarium handbook. The Royal Botanic Garden, London. $334 p$.

Brummit RK \& Powell CE (1992) Authors of plants names. The Royal Botanic Gardens, Kew. 732p.

Cabrera LI, Salazar GA, Chase MW, Mayo SJ, Bogner J \& D'Ávila P (2008) Phylogenetic relationships of Aroids and Duckweeds (Araceae) inferred from coding and noncoding plastid DNA. American Journal of Botany 95: 1153-1165.

Coelho MAN, Sakuragui CM, Gonçalves EG, Temponi LG \& Valadares RT (2009) Araceae. In: Stehmann JR, Forzza RC, Salino A, Sobral M, Costa DP \& Kamino LHY (eds.) Plantas da Floresta Atlântica. Jardim Botânico do Rio de Janeiro, Rio de Janeiro. Pp. 141-145.

Engler A \& Krause K (1908) Monsteroideae. In: Engler A (ed.) Das Pflanzenreich IV 23 B[b]. W. Engelmann, Berlin, Leipzig. Pp 5-140.

Grayum MH (1990) Evolution and phylogeny of the Araceae. Annals of the Missouri Botanical Garden 77: 628-697.

Gonçalves EG \& Temponi LG (2004) A new Monstera (Araceae: Monsteroideae) from Brazil. Brittonia 56: 72-74.

Henriquez CL, Arias T, Pires JC, Croat TB \& Schaal BA (2014) Phylogenomics of the plant family Araceae. Molecular phylogenetcs and evolution 75: 91-102.

IBGE - Instituto Brasileiro de Geografia e Estatística (2010) Estados: Paraná, censo 2010. Disponível em < http://www.ibge.gov.br/Estado sat/>. Acesso em 23 agosto 2013.

Karney AP \& Grayum MH (2012) A new Monstera species (Araceae) of economic importance from Honduras. Economic Botany 66: 207-213.

Keating RC (2004) Vegetative anatomical data and its relationship to a revised classification of the genera of Araceae. Annals of the Missouri Botanical Garden 913: 485-494.

Lorenzi H \& Souza HM (1995) Plantas ornamentais do Brasil: arbustivas, herbáceas e trepadeiras. Plantarum, Nova Odessa. 720p.

Maack R (1981) Geografia física do estado do Paraná. José Olympio, Curitiba. 450p.

Madison MT (1977) A revision of Monstera (Araceae). Contributions from The Gray Herbarium of Harvard University 207: 1-100.

Mayo SJ, Bogner J \& Boyce PC (1997) The genera of Araceae. Royal Botanic Gardens, Kew. 370p.

Myers N, Mittermeier RA, Mittermeier CG, da Fonseca GAB \& Kent J (2000) Biodiversity hotspots for conservation priorities. Nature 403: 853-858.

Radford AE, Dickison JR, Massey JR \& Bell CR (1974) Vascular plant systematics. Harper \& Row Publishers, New York. 891p.

Roderjan C, Galvão F, Kuniyoshi YS \& Hatschbach GG (2002) As unidades fitogeográficas do estado do Paraná. Ciências \& Ambiente 24: 75-92.

Soares Morais MLC (2008) Sistemática e ecologia de Heteropsis Kunth (Araceae Juss.) com destaque especial nas espécies ocorrentes na Reserva Florestal Adolpho Ducke, Manaus, Amazonas, Brasil. Tese de Doutorado. Instituto Nacional de Pesquisas da Amazônia, Universidade Federal do Amazonas, Manaus. 191p.

Soares ML, Mayo SJ \& Gribel R (2013) A preliminary taxonomic revision of Heteropsis (Araceae). Systematic Botany 38: 925-974.

Souza VC \& Lorenzi H (2012) Botânica sistemática: guia ilustrado para identificação das famílias de fanerógamas nativas e exóticas no Brasil, baseado em APG III. 3 ${ }^{\text {a }}$ ed. Instituto Plantarum, Nova Odessa. 768p.

Stearn WT (2004) Botanical Latin. $4^{\text {th }}$ ed. Timber Press, Inc., Portland. 546p.

Tam SM, Boyce PC, Upson TM, Barabe D, Brunear A, Forest F \& Parker JS (2004) Intergeneric and infrafamilial phylogeny of subfamily Monsteroideae (Araceae) revealed by chloroplast trnL-F sequences. American Journal of Botany 91: 490-498.

Thiers B [continuamente atualizado]. Index Herbariorum: A global directory of public herbaria and associated staff. New York Botanical Garden's Virtual Herbarium. Disponível em $<$ http://sweetgum.nybg. org/ih/>. Acesso em 9 junho 2016. 


\section{Lista de exsicatas}

Britez RM 779, 1830 (3). Cardozo AP 92 (3) 91 (4). Caxambu MG 875 (3). Engels ME 1526 (1), 2367 (2). Ferneda Rocha LC 87 (3), 88 (1), 284 (4). Gatti ALS 260, 261 (3). Gatti G 468 (3), 318 (4). Hatschbach G 13555, 20901, 25763, 8696, 6414 (1), 33642 (2), 960, 34290, 46084, 57133, 29630, 46251, 19242, 16374 (3). Kersten R 2001 (3). Kozera C 1320 (1), 1069, 1070, 1107 (3). Krierger Pe L 11094 (2), 13344 (3). Lindeman JC 2125 (4). Pereira SF 260 (3). Reitz PR 5737 (3). Roderjan CV 1281 (3). Smith LB 3931 (3). Souza WS 561, 688 (3). Temponi LG 922 (1). Ziller SR 849 (3). 